\title{
Eutrophication and climate warming alter spatial (depth) co-occurrence patterns of lake phytoplankton assemblages
}

\author{
Francesco Pomati - Blake Matthews • Ole Seehausen • \\ Bas W. Ibelings
}

Received: 25 November 2015/Revised: 5 September 2016/Accepted: 6 September 2016/Published online: 14 September 2016

(C) Springer International Publishing Switzerland 2016

\begin{abstract}
The composition and dynamics of plankton communities are critically affected by human-induced environmental changes. We analysed 33 years of phytoplankton monthly data collected in Lake Zurich (Switzerland), assigning organisms (genus level) to taxonomic groups (class, family), Reynolds associations and size categories. The aim was to understand how eutrophication and climate change have influenced taxa co-occurrence patterns within and between groups
\end{abstract}

Handling editor: Judit Padisák

Francesco Pomati and Blake Matthews have contributed equally to the work.

Electronic supplementary material The online version of this article (doi:10.1007/s10750-016-2981-6) contains supplementary material, which is available to authorized users.

\section{F. Pomati $(\bowtie)$}

Department of Aquatic Ecology, Eawag: Swiss Federal Institute of Water Science and Technology, Uberlandstrasse 133, 8600 Dübendorf, Switzerland e-mail: francesco.pomati@eawag.ch

B. Matthews - O. Seehausen - B. W. Ibelings Centre for Ecology Evolution and Biogeochemistry, Eawag: Swiss Federal Institute of Water Science and Technology, Seestrasse 79, 6047 Kastanienbaum, Switzerland

B. W. Ibelings

Institut F.-A. Forel, Université de Genève, Versoix, Switzerland over the lake water column (14 depths, 0-135 m), using null-models to test for non-random spatial (depth) assembly. We found that the whole community showed high taxa co-occurrence levels, significantly deviating over time from random assembly concurrently with lake warming and reduced nutrient loading. This pattern was driven mostly by the depth structure of metalimnetic assemblages during summer and autumn. The prevalence of non-random spatial patterns changed for different taxonomic and functional groups, with only few significant deviations from null-model expectations. Within taxonomic and functional groups (particularly Classes and size categories), the frequency of spatial overdispersion of taxa decreased over time while the frequency of clustering increased. Our data suggest that the relative importance of mechanisms determining phytoplankton metacommunity dynamics have changed along with environmental gradients shaping water column structure.

Keywords Phytoplankton - Co-occurrence . Variance ratio - Eutrophication - Climate change Community assembly

\section{Introduction}

Understanding the processes that govern long-term changes in the structure and composition of natural communities has always been a fundamental 
challenge in ecology (Diamond, 1975), but it is increasingly important in light of anthropogenic impacts on biodiversity and ecosystem services (Cardinale et al., 2012). Despite a rich history of both community assembly theory and practice, we still lack the long-term series of data necessary to assess how human impacts influence the processes that generate, maintain, and change biodiversity (Magurran et al., 2010; Vonlanthen et al., 2012). Such time-series are critical for understanding the relative influence of stochastic and deterministic processes in governing community assembly across broad environmental gradients over both space and time (Chase et al., 2011; Gravel et al., 2011; Kathleen Lyons et al., 2015).

In a series of previous studies, several authors have analysed a dataset from the mesotrophic peri-alpine Lake Zurich (Switzerland), featuring monthly water samples taken at different depths for more than 30 years in conjunction with environmental variables, to understand how climate warming and re-oligotrophication influenced lake physics, chemistry and plankton community structure (Livingstone, 2003; Anneville et al., 2004; Matthews \& Pomati, 2012; Pomati et al., 2012, 2015). Such investigations have highlighted that, over the past three decades, climate warming and re-oligotrophication in Lake Zurich have occurred alongside: (i) an increase in thermal stability of the water column and reduced deep mixing (Livingstone, 2003; Posch et al., 2012), (ii) a change in phytoplankton community composition (Anneville et al., 2004), (iii) an increase in number of plankton taxa possibly due to reduction in phosphorus inputs combined with climate warming-mediated enhancement of resource heterogeneity over the water column (Pomati et al., 2012), (iv) a decrease in annual species turnover (Matthews \& Pomati, 2012), and (v) an increase in the annual prevalence of taxa while the abundance of both rare and common taxa declined (Pomati et al., 2015). Overall, the phytoplankton data suggested a trend of decreasing dominance, with more taxa coexisting simultaneously in the water column of the lake, and potential changes in the mechanisms driving community assembly.

In this study, we use a statistical approach to study the spatial (depth) structure of phytoplankton assemblages over the water column of Lake Zurich (Fig. 1), during the directional environmental change characterising the recent lake history. The aim was to test for non-random taxa co-occurrence patterns to gauge spatial underdispersion (i.e. clustering) and overdispersion of organisms at the entire community level and within taxonomic groups, ecological associations and trait-based categories. Clustering and overdispersion are defined as a tendency for taxa or groups to co-occur at different sites (depths) with an expectancy larger/ smaller than predicted by appropriate null models of random assembly (Emerson \& Gillespie, 2008; Cadotte et al., 2013). Studying community over/ underdispersion may allow us to link changes in patterns to the interplay of the potential underlying mechanisms (dispersal, environmental filtering and species interactions) (HilleRisLambers et al., 2012). For example, we expect that environmental filters will frequently result in the spatial clustering of similar organisms, while strong and negative species interactions might lead to spatial overdispersion of species with similar traits (Emerson \& Gillespie, 2008; Cavender-Bares et al., 2009; Kraft \& Ackerly, 2010; Kathleen Lyons et al., 2015). In most cases, neutral processes (e.g. ecological drift, dispersal limitation) will generate random co-occurrence patterns for both trait and taxonomic groupings (Rosindell et al., 2011). There can be however interactions among mechanisms and many exceptions to these predictions (Bell, 2005; Mayfield \& Levine, 2010). Teasing apart the processes that determine diversity in ecological communities is in fact an ongoing challenge (Kraft et al., 2014). Nevertheless, the above approach has demonstrated useful for investigating the relative importance of different mechanisms involved in community assembly in many cases (Gotelli \& McCabe, 2002; Bell, 2005; Adams, 2007; Emerson and Gillespie Emerson \& Gillespie, 2008; Livingston \& Philpott, 2010; Weiher et al., 2011; Kathleen Lyons et al., 2015).

To study co-occurrence patterns, we use null-model simulations of random assembly that account for differences in site suitability over the water column and temporal changes in the size of the species pool (Gotelli, 2000; Kathleen Lyons et al., 2015). We analyse depth co-occurrence (clustering and overdispersion) for the whole phytoplankton community, regardless of any taxonomic or functional affiliation, and compare co-occurrence patterns among and within taxonomic groups, Reynolds ecological associations and size categories (Fig. 1). Such analyses can provide hypotheses on how directional environmental change, through the combined effects of re- 


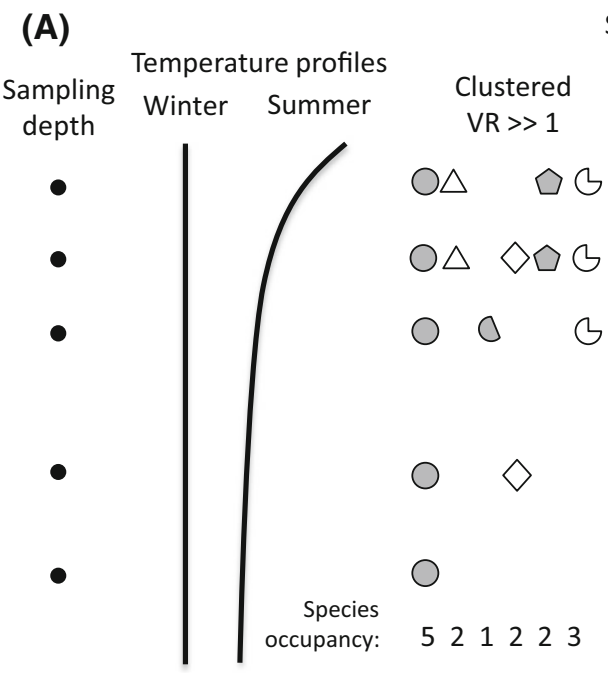

Species Pool: $\bigcirc \triangle ৩ \diamond \triangle ৫$

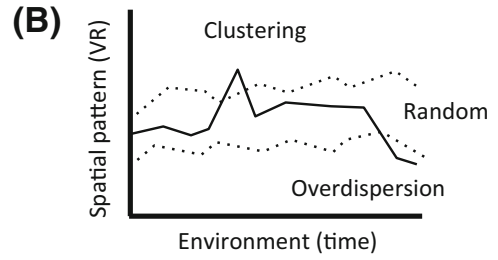

Fig. 1 Schematic description of the approach used to study taxa co-occurrence patterns. A Several depths were sampled over the vertical structure of the lake water column, which changed according to the season and across years (temperature profiles); phytoplankton taxa differently occupied depth habitats (depths occupancy) and showed to consistently share such habitats with other taxa (clustering), not to be associated with other taxa

oligotrophication and climate warming, can modify phytoplankton vertical structure in a deep lake and potentially community assembly (Emerson \& Gillespie, 2008; Cadotte et al., 2013).

\section{Materials and methods}

Data

The phytoplankton dataset consists of microscopic counts of samples collected from 1976 to 2008 in monthly intervals $(n=396)$ at one site (centre of the lake in front of Thalwil in Lake Zurich) at 14 different water depths: $0,1,2.5,5,7.5,10,12.5,15,20,30,40$, $80,120,135 \mathrm{~m}$. Data were collected consistently by the Zurich Water Supply Company (WVZ). For more details about sampling methods, please refer to

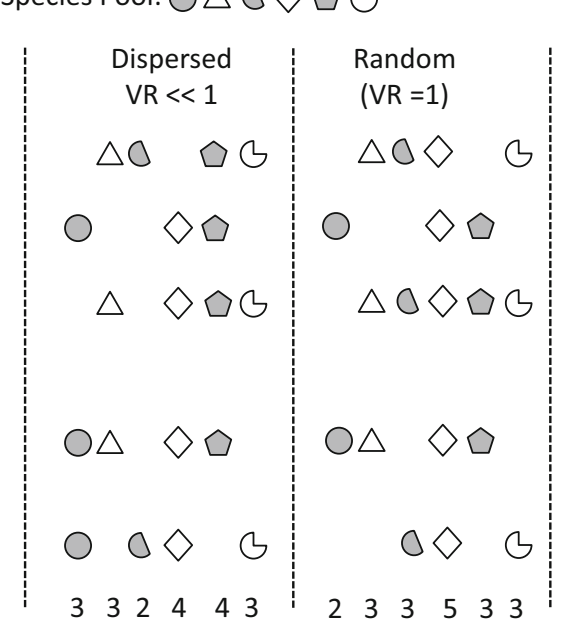

(C)

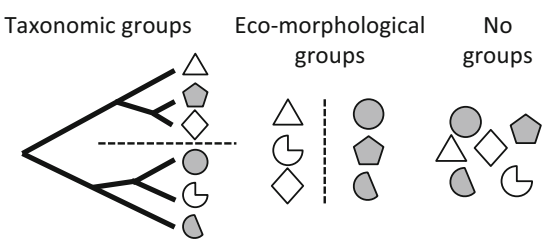

(dispersion), or to be randomly distributed. B We analysed these taxa associations using their variance-ratio (VR) over depths for each date of the time-series and compared it to expected patterns from null-model (random) assumptions. C Patterns were studied for all organisms regardless of their affiliation, within taxonomic groups at different scales and within eco-morphological groups

(Pomati et al., 2012, 2015). Taxonomy of all species in the dataset was harmonised according to the modern phytoplankton classification (for details about how the temporal dataset was homogenised see (Pomati et al., 2012, 2015), the latter reference reports also detail about how we dealt with potential inconsistency in taxonomic classification). In this study, we classified each species into ecological associations following the system proposed by Reynolds and others (Reynolds et al., 2002; Padisák et al., 2009). Reynolds categories represent combinations of species based on similar morphological and physiological traits, and similar ecological requirements (high affinity for phosphorus or $\mathrm{CO} 2$, requirement of skeletal silicon, motility, mixotrophy etc.) (Padisák et al., 2009; Reynolds et al., 2002). Apart from Reynolds categories, we decided to work for the rest of the study using genus level classification of taxa to reduce potential biases in the taxonomic classification 
of certain phytoplankton species, which was previously documented for the long lake Zurich time-series (Pomati et al., 2015).

We also built phytoplankton categories independent of taxonomic affiliation by grouping genera into clusters based on genus median biovolumes $\left(\log _{10}\left(\mu \mathrm{m}^{3}\right)\right.$ of each counted taxon, corresponding to a natural unit of colonies in case of colonial forms, and to individual cells for non-colonial taxa), using the database published by Kremer et al. (2014). When species were missing in the database, natural unit biovolumes were obtained from the Eawag database (H.R. Buergi, unpublished-see online Supporting Information, Table S1). To create trait-based groups, we chose biovolume (hereafter size) because of its importance in phytoplankton resource acquisition, predator avoidance and reproduction (Litchman \& Klausmeier, 2008). To build size categories, we used unsupervised model-based clustering as provided by the $\mathrm{R}$ package mclust (R-Development-Core-Team, 2015), applying maximum likelihood estimation and Bayes criteria to identify the most likely model and number of clusters (Fraley \& Raftery, 2002; Pomati et al., 2013). The list of phytoplankton species and their corresponding classification into taxonomic groups, Reynolds associations and size categories is available as online Supporting Information (Supporting Tables, Table S1).

\section{Phytoplankton community analysis}

As mentioned above, we used genera as our basal taxonomic unit of study, and analysed co-occurrence patterns at different levels of taxonomic resolution and eco-morphological groupings. We calculated the variance ratio (VR) of presence/absence matrices (genera $\times$ depths) for each sampling date, to test for non-random patterns in the co-occurrence of genera (Fig. 1). The VR is defined as the variance in the total number of taxa or groups over sites (depths) divided by the sum of between-site variances in individual taxa or groups (Seehausen \& Schluter, 2004). In our study, high VRs indicate spatial clustering in the water column and low VRs indicate spatial overdispersion (Fig. 1). First, we calculated VRs for the entire community to test for non-random spatial distribution of the whole phytoplankton, and tested whether patterns were driven by the most common organisms compared to the rare genera $(25 \%$ most common and
$50 \%$ least prevalent genera, respectively, decided based on genera prevalence distributions in the whole dataset). Then, we calculated VRs within Kingdoms, Families, Classes, Reynolds associations and size categories, across all depths for each sampling event over the whole time series to assess co-occurrence of taxonomically and eco-morphologically similar taxa (Fig. 1).

We compared observed VRs to a null-model in which sites (depths) differed in their generalised suitability and genera differed in their likelihood of appearing at each site (SIM8 in (Gotelli, 2000) where the probability of site occupancy $P\left(a_{i j}\right)=S_{i} T_{j} / N^{2}$, with $N$ is the matrix total, $S_{i}$ is the total for row $i, T_{j}$ is the total for column $j$ ). For studying the VR of taxa over time, we used all the lake depths as sites at each sampling date. We considered significant clustering and overdispersion to be present when the observed VR was greater or smaller than $95 \%$ of the null distributions, respectively, and calculated (i) the frequency of significant clustering and overdispersion over the water column for each sampling date, and (ii) the percentage of sampling dates where each group showed significant deviation from null-model distributions. To study VR over the water column of the lake, at each date we calculated observed VR and nullmodel expected values within a window of 4 depths that from top to bottom slides over the 14 sampled depths. Increasing or decreasing the size of the moving window between 3 and 6 depths did not change the observed patterns (data not shown).

\section{Environmental change}

The lake Zurich dataset included physico-chemical variables measured over the water column (Pomati et al., 2012). Here, we used the first principal component (PC1) of lake environmental change, calculated by principal component analysis of scaled water-column values of temperature, conductivity, $\mathrm{pH}, \mathrm{P}-\mathrm{PO}_{4}{ }^{3-}, \mathrm{N}-\mathrm{NO}_{3}{ }^{-}$and light absorption, to help explain variation in patterns in taxa spatial cooccurrence. These six water variables were chosen based on their measured consistency at all sampling depths over the whole time-series, their relevance as habitat conditions or plankton nutrients and their low cross-correlation (Pomati et al., 2012). PC1 loadings were $0.65,0.30,-0.13,-0.31,-0.35$, and -0.48 for temperature, $\mathrm{pH}$, light, $\mathrm{P}-\mathrm{PO}_{4}$, conductivity and $\mathrm{N}-$ 
$\mathrm{NO}_{3}$, respectively. For presentation purposes, timeseries were decomposed in long-term trend, seasonal and residual variation by locally weighted scatterplot smoothing (Cleveland et al., 1990). Data analysis and graphics were performed in the R statistical programming language (R-Development-Core-Team, 2015).

\section{Results}

At the entire community level, phytoplankton genera tended to be more spatially (depth) aggregated than expected by chance (Fig. 2). Although our null-model accounted for differences in site suitability, the most dominant pattern at the community level was strong spatial clustering of phytoplankton genera over the water column (Fig. 2A). This pattern characterised the

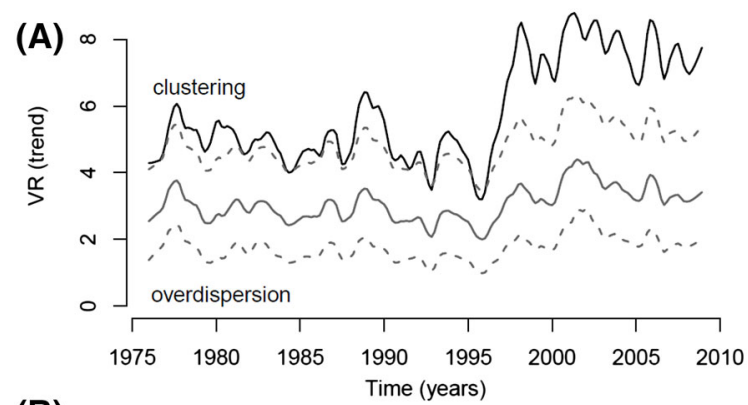

(B)

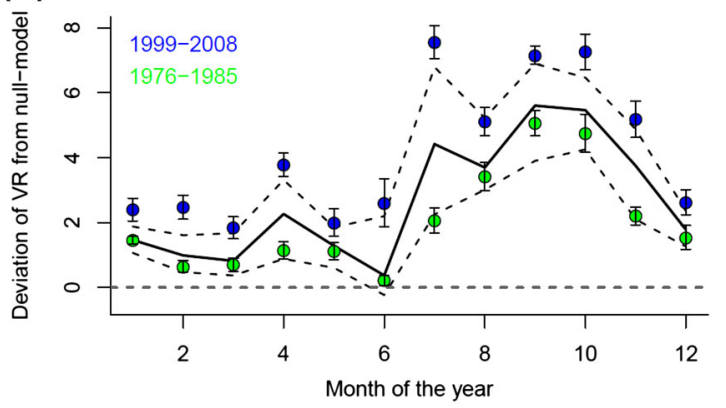

Fig. 2 Observed VR between all phytoplankton taxa in Lake Zurich compared to null-model simulation (conditional probability model SIM8 Gotelli, 2000). A VR long-term trends (black solid line) compared to null-model median (grey solid line) and relative $95 \%$ confidence intervals (grey dotted lines); time series were decomposed as reported in Methods. B Seasonal change in deviation of observed VR from null-model simulated median: black lines represent observed VR distribution median (solid), first and third quartiles (dashed) for the whole dataset; green and blue dots represent average VR levels and their standard error for the first and last 10 years of the time series, respectively; horizontal grey dashed line highlights no deviation, data above the line signal clustering whole accounted lake history, but markedly increased in frequency towards the end of the time series (after mid-1990s, Fig. 2A). Clustering was particularly evident during the summer and autumn months (Fig. 2B) and the overall level changed over the long term, with stronger deviation from null-model expectations in the most recent 10 years (blue dots, Fig. 2B). Later in the time series, clustering was more pronounced during spring (the onset of water column stratification) and early summer (months 4 and 7 , Fig. 2B). Patterns of spatial clustering were driven by the most common genera (high prevalence quartile, $n=42$, see Fig S1 in Supporting Information), while rare genera $(50 \%$ least common, $n=81)$ exhibit mostly random patterns in their long-term and seasonal trends, with a slight tendency towards overdispersion (Fig. S2 in Supporting Information).

The first principal component of lake environmental change, which was mainly driven by water temperature, remained rather stable during the 1970s and early 1980s, showing a steep decrease to negative values in the late 1980s and after then a steady increase till the end of our analysed time series, with a transition from negative to positive values in the middle of 1990s (Fig. 3A). Seasonally, PC1 showed to be negative in winter and positive in summer time (Fig. 3B), and it increased over the time series with higher values in the most recent 10 years (blue dots, Fig. 3B). Both seasonal and long-term patterns of PC1 and VR were strikingly similar (Figs. 2, 3). Over the whole time series, in fact, significant non-random spatial aggregation increased with higher levels of $\mathrm{PC} 1$, suggesting an effect of water temperature on the intensity of phytoplankton taxa co-occurrence (Fig. 3C).

Since the observed changes in the phytoplankton spatial aggregation appeared to be related to seasonal and long-term variation in the environmental conditions of the water column (Fig. 3), we investigated how phytoplankton community patterns changed over the lake depths (Fig. 4). Deviation of taxa co-occurrence levels from null-model simulations were lowest in the epilimnion $(<10 \mathrm{~m})$ and increased over the meta- (15-30 m) and hypolimnion (40-136 m, Fig. 4A). These depth patterns did not significantly change over time in the epiliminion, but taxa cooccurrence markedly increased in the meta- and hypolimnion towards the end of the time series (Fig. 4A). Clustering of taxa was particularly evident 

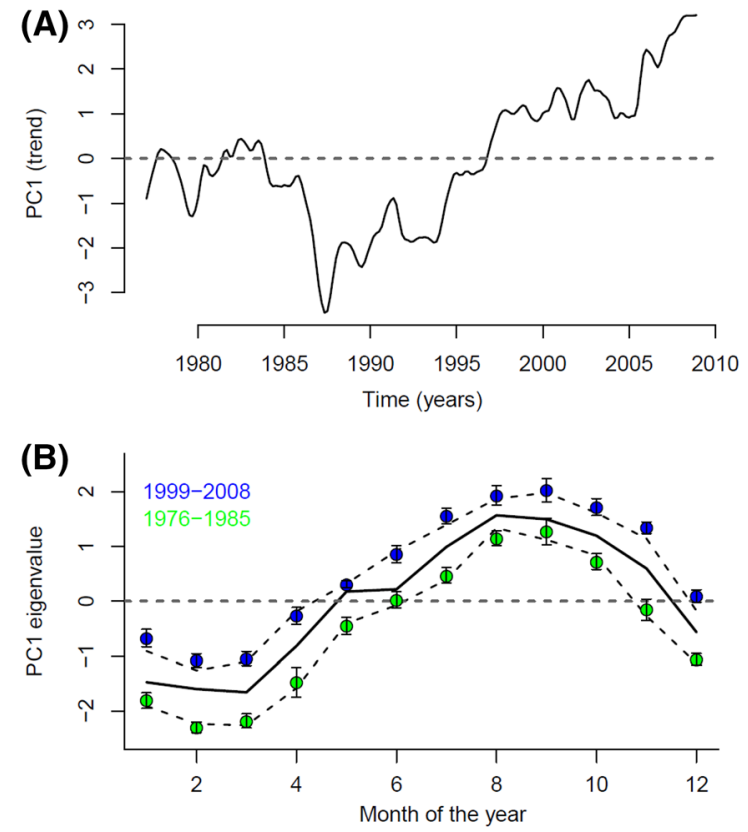

(C)

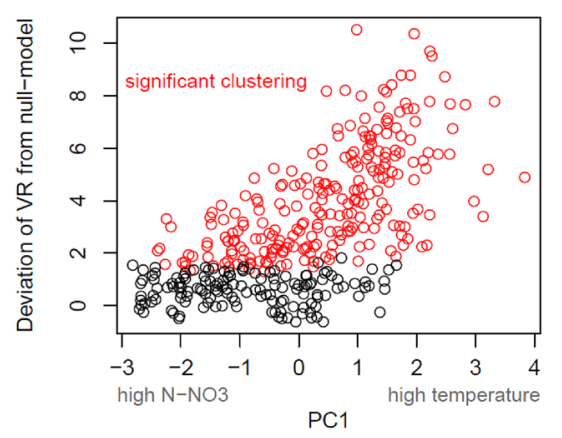

Fig. 3 A Long-term trends of PC1, the time series was decomposed as reported in Methods. B Seasonal change in PC1 levels: black lines represent PC1 distribution median (solid), first and third quartiles (dashed) for the whole dataset; green and blue dots represent average PC1 levels and their standard error for the first and last 10 years of the time series, respectively. C Correlation between deviation of observed VR between all phytoplankton taxa from null-model simulated median and PC1 values across the entire time series. Significant spatial aggregation (above $97.5 \%$ interval of null-model simulation) is highlighted in red. PC1 strongest loadings were temperature $(0.65)$ and $\mathrm{N}-\mathrm{NO}_{3}(-0.48)$, see Methods and Pomati et al. (2012) for more detail

during the summer and autumn months in the metalimnion and in the hypolimnion during winter (Fig. 4B).

Patterns of taxa co-occurrence varied with the taxonomic scale of analysis (Fig. S3, Supporting Information). We studied phytoplankton co-occurrence patterns over depth focusing on the variance ratios calculated within taxonomic groups (Families and Classes), Reynolds ecological associations and size categories. The frequency of non-random spatial patterns varied considerably between Families, Classes, Reynolds categories and size-groups and over time (Fig. 5). Most taxonomic and trait-based groups of phytoplankton did not show significant deviation from null-model simulated patterns, since significant deviation from random occurred for about $4 \%$ of Families, $10 \%$ of Classes, $6 \%$ of Reynolds groups, and $15 \%$ of size-groups.

Unlike generalised spatial aggregation patterns detected at the entire community level, within taxonomic and trait-based groups overdispersion was relatively common (grey lines in Fig. 5), and in most cases decreased in frequency over time. By comparison, levels of clustering within groupings (black lines in Fig. 5) were less common, and increased towards the end of the time series (with an exception for phytoplankton Families, Fig. 5A), with an evident shift of prevalence from overdispersion to clustering for Classes and size-groups (Fig. 5BD). Within the Families, Classes, Reynolds categories and size-groups that showed either significant clustering or overdispersion, such patterns only occurred in less than $10 \%$ of the sampling dates, with few exceptions (Fig. S4 and Tables S2-S5, Supporting Information).

\section{Discussion}

In deep water bodies, the vertical structure of the water column represents the most heterogeneous dimension of phytoplankton spatial ecology (Litchman \& Klausmeier, 2008). Contrasting gradients of essential resources can cause a heterogeneous spatial distribution of phytoplankton groups over the water column: light attenuates with depth, light spectrum changes and nutrients are generally richer in the deeper water layers (Klausmeier \& Litchman, 2001; Stomp et al., 2004; Reynolds, 2006; Longhi \& Beisner, 2009). The partitioning of phytoplankton over a stratified water column and the occurrence of assemblages of plankton in persistent water layers have been documented in lakes and oceans (Klausmeier \& Litchman, 2001; Reynolds, 2006; Durham \& Stocker, 2012). Changes in the dispersal of organisms and in the distribution of resources over depths are dependent on the structure 


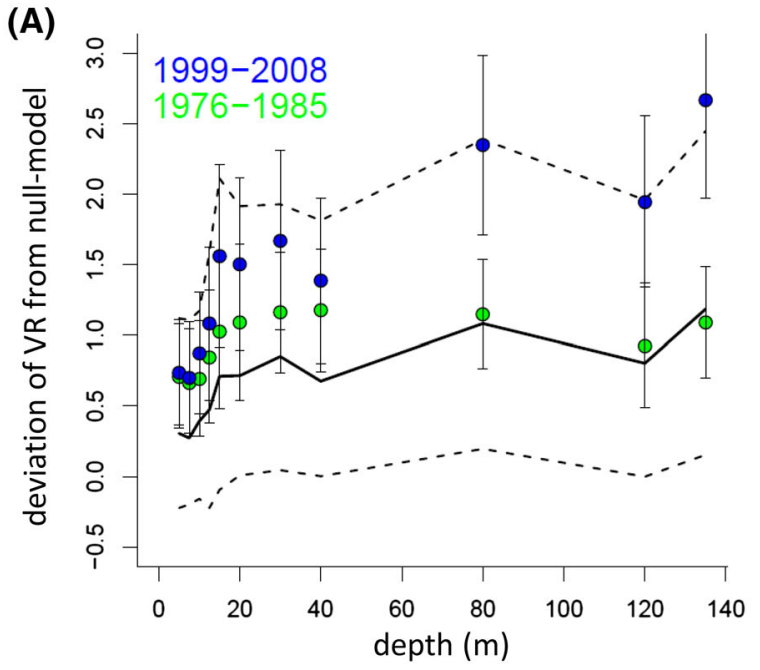

Fig. 4 Deviation of observed VR from null-model simulated median over Lake Zurich depths: A black lines represent median values (solid), first and third quartiles (dashed) over the whole dataset; green and blue dots represent average levels and their standard error for the first and last 10 years of the time series,
(B)

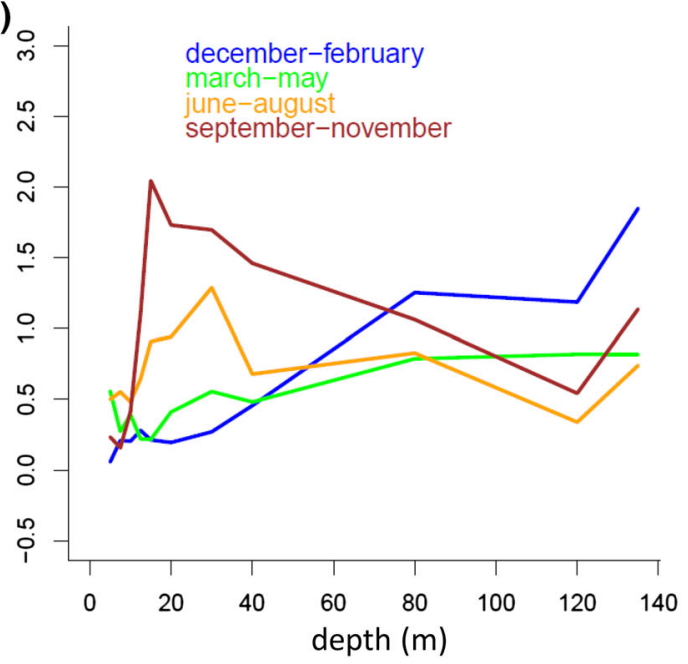

respectively; B coloured lines represent observed VR distribution median for the whole dataset during different seasons. VR and null models were calculated in windows of 4 depths moving from surface to bottom over the water column
Fig. 5 Percentage of phytoplankton Families (A, $n=79)$, Classes (B, $n=18)$, Reynolds categories $(\mathbf{C}, n=30)$ and size-based-groups (D, $n=8$ ) showing significant (outside confidence limits of null-model) clustering (black line) and overdispersion (grey line) during the time series. Time series were decomposed (see Methods) and solid lines represent trends
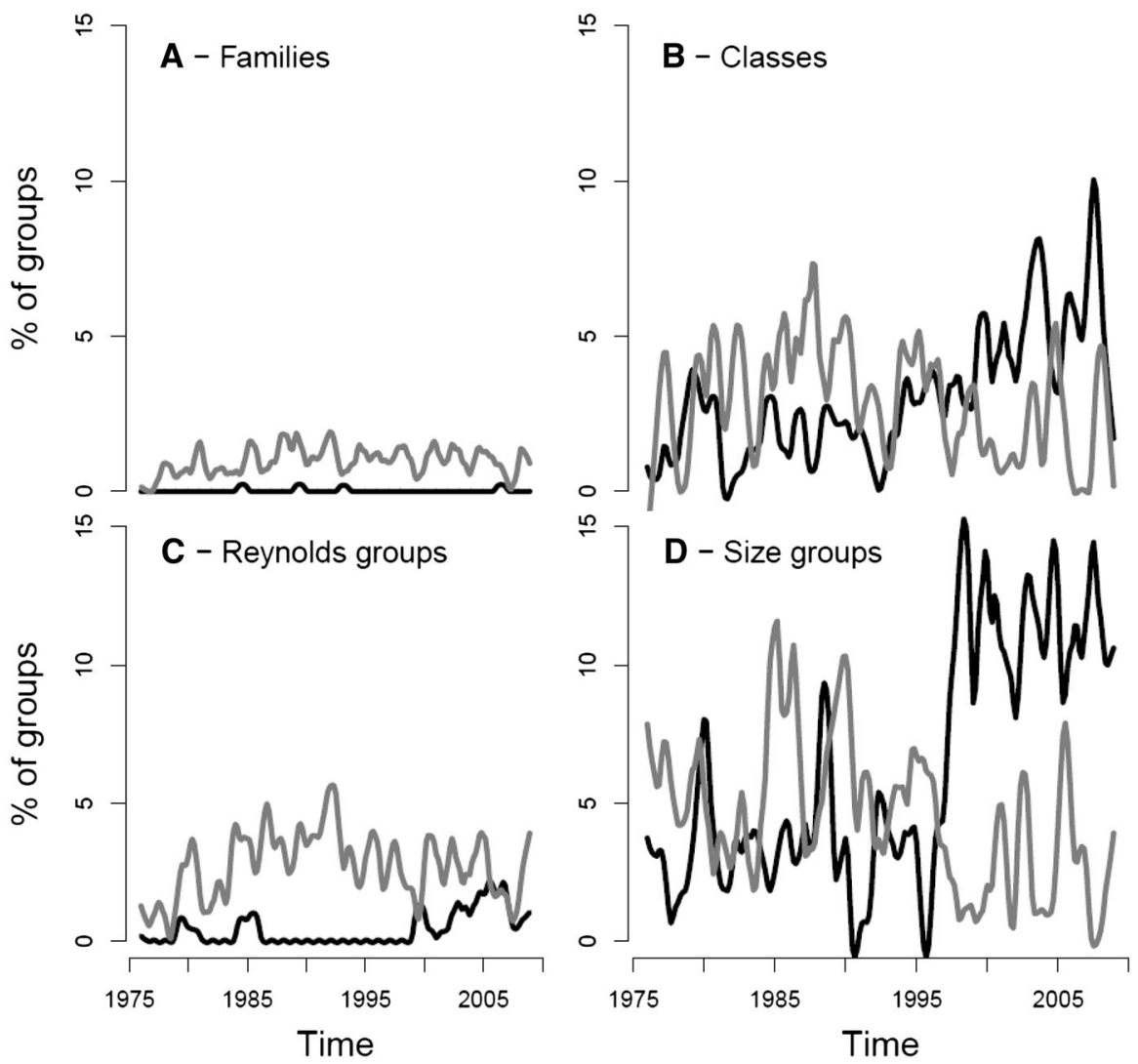
and stability of the water column, which have a seasonal pattern: in summer-autumn the water column is stratified and more stable and nutrients tend to become depleted in the photic zone (Reynolds, 2006).

In our data, we observed a seasonal pattern of increasing deviation from random community assembly during summer and autumn months in lake Zurich (Fig. 2B), apparently associated with metalimnetic assemblages of phytoplankton (Fig. 4B) and mirrored by a similar trend over the time series (Fig. 2A). For algal Classes and size categories, overdispersion of genera was more common early in the time series with clustering of genera increasing in frequency late in the time series (this pattern was also slightly evident for Reynolds categories, Fig. 5B-D). Overdispersion was more frequent than clustering within phytoplankton Families and Reynolds associations (Fig. 5A, C), suggesting the presence of negative interactions (e.g. competition) among supposedly similar taxa within these groups (Emerson \& Gillespie, 2008; CavenderBares et al., 2009; Kraft \& Ackerly, 2010; Kathleen Lyons et al., 2015). Overall the data indicated that, within broad taxonomic and functional groups as well as for the whole community, environmental change has increased spatial clustering of taxa around certain depths. This signal of deviation from random spatial assembly correlated with changes in the physics (temperature) and chemistry $\left(\mathrm{NO}_{3}\right)$ of the water column (Fig. 3). Lake Zurich environmental changes have been strongly driven by water temperature, which in turn affected the strength and stability of thermal stratification (Livingstone, 2003) and the distribution of essential nutrients (Pomati et al., 2012). This suggests an effect of water column stratification on taxa co-occurrence patterns.

Previous work has shown that lake Zurich, during the same period of time of this study, changed towards a more stably stratified lake with a significant decrease in the frequency and depth of water column mixing (Livingstone, 2003; Posch et al., 2012). These changes, together with reduction in free available phosphorus and limited variation in light penetration (Pomati et al., 2012), have shifted algal blooms from the epi- to the metalimnion (Posch et al., 2012). Since the 1990s, the metalimnetic assemblage in lake Zurich has been dominated by the cyanobacterium Planktothrix rubescens (de Candolle ex Gomont) Anagnostidis et Komárek" (accounts for circa 40\% of the yearly phytoplankton biomass) (Posch et al., 2012).
This is a low-light/deep light-spectrum and lowtemperature adapted species able to regulate buoyancy and position itself at the interface between epi- and hypolimnion, to exploit the nutrients available at depth (Posch et al., 2012). Our result confirm that, at the end of the time series and particularly for the metalimnion, an increase in water column stability and resource heterogeneity over depths may have interacted to change phytoplankton taxa co-occurrence patterns, which significantly departed from random assembly (Figs. 2, 4).

There are different potential mechanisms that might have influenced the observed long-term patterns in lake Zurich taxa co-occurrence. On one hand, environmental filtering due to re-oligotrophication and warming of the lake might have increased in its importance relative to species interactions (or dispersal-driven dynamics) at the end of the time series, favouring clustering of taxa within and between groups over depths where the supply of essential resources was optimal for phytoplankton growth (Klausmeier \& Litchman, 2001). This pattern is consistent with previous work showing that eutrophic systems are characterised by stronger competition than low-productivity environments, because nutrient enrichment forces organisms to compete mainly for light and reduces the opportunity for partitioning of strategies within the same spatial niche (Mittelbach et al., 2001; Hautier et al., 2009; Ryabov \& Blasius, 2011). These considerations are supported by a recent study on Lake Constance, in which re-oligotrophication and warming caused a shift from compensatory (exclusion) to synchronous (co-occurrence) temporal dynamics in phytoplankton biomass (Jochimsen et al., 2012).

On the other hand, our analysis highlighted that non-random patterns in taxa co-occurrence over depth arise rarely. The high prevalence of random spatial patterns within taxonomic and functional groups may have been due to a residual bias in the classification of some organisms (Pomati et al., 2015). Our results were however driven by dynamics of the most common genera, which were the most consistently counted, classified, and monitored taxa over the long time series (Pomati et al., 2015). The highest frequency of nonrandom co-occurrence patterns was observed within size classes, highlighting how a functional trait-based approach may unravel deterministic patterns in the phytoplankton assemblages (Litchman \& Klausmeier, 
2008). More information on the traits of natural phytoplankton populations and how they are distributed among taxonomic groups may help to disentangle such effects (Edwards et al., 2012, 2013; Pomati et al., 2013). Nevertheless, the majority of groups and sampling dates did not significantly deviate from our null-model simulation, suggesting stochastic processes play an important role in phytoplankton dynamics.

Dispersal, landscape heterogeneity and spatial aggregation are important factors influencing population dynamics, species coexistence and community assembly processes (Colwell \& Rangel, 2009; Hart \& Marshall, 2009; Fukami, 2010; Edwards \& Stachowicz, 2011; Rosindell et al., 2011). A decrease in mixing frequency and depth, as highlighted in the recent history of lake Zurich by previous studies (Posch et al., 2012; Livingstone, 2003), may have changed the frequency and strength of dispersal among water layers reducing source-sink effects and homogenisation of the assemblages, diminishing the signal of random assembly (Leibold et al., 2004; Rosindell et al., 2011). Such signal mostly affected common genera, with rare taxa showing no significant change in their spatial structure (Fig. S1-2, Supporting Information). Common taxa in a spatial landscape are known to provide the core populations at the different sites, with rare taxa being subjected to stochastic dispersal processes (Livingston \& Philpott, 2010; White et al., 2010).

Once water layers are formed, aggregation and growth within a layer can modify the relative strength of intra- and interspecific competition by changing the ratio of conspecific to heterospecific competitive encounters. Previous work suggests that spatial aggregation can strengthen dispersal limitation and intraspecific competition, favouring the coexistence of weak and strong competitors, as well as specialists and opportunists (Adler \& Drake, 2008; Hart \& Marshall, 2009; Shen et al., 2009; Edwards \& Stachowicz, 2011; Ryabov \& Blasius, 2011). This would explain our general signal of increasing spatial clustering, which could also filter taxa by allowing only similar competitors to coexist as a consequence of slower competitive exclusion and semi-neutrality (Scheffer \& van Nes, 2006; Vergnon et al., 2012). In that case, we would expect to see also a pattern of increase in clustering within both taxonomic and traitbased groups, which was evident from the VR trends within Classes and size categories in our data (Fig. 5B, D). These considerations may also be relevant for explaining the striking increase in algal richness detected in the Lake Zurich dataset over the past 3 decades (Pomati et al., 2012, 2015).

In conclusion, our study suggests that dispersal and metacommunity dynamics may be the important processes determining non-random patterns in taxa co-occurrence, and finally community assembly, in phytoplankton from deep lakes. Future work should study phytoplankton communities with a dynamics metacommunity approach (Leibold et al., 2004), addressing to what extent deterministic sorting of species in water layers based on their traits interacts with dispersal limitation, altering community dynamics.

Acknowledgments We thank O. Koster (WVZ) for providing access and valuable insights to the Lake Zurich data, R. Ptacnik for critically reviewing the manuscript, and the anonymous reviewers for their constructive suggestions. FP research was in part supported by Eawag action field project Aquaprobe to BWI and OS.

Author Contributions OS and BWI originally formulated the idea; FP prepared the data; FP and BM performed statistical analyses; FP drafted the manuscript; all authors commented on the manuscript.

\section{References}

Adams, D. C., 2007. Organization of Plethodon salamander communities: guild-based community assembly. Ecology 88: $1292-1299$.

Adler, P. B. \& J. M. Drake, 2008. Environmental variation, stochastic extinction, and competitive coexistence. The American Naturalist 172: 186-195.

Anneville, O., S. Souissi, S. Gammeter, D. Straile \& S. M. D. Wimereux, 2004. Seasonal and inter-annual scales of variability in phytoplankton assemblages: comparison of phytoplankton dynamics in three peri-alpine lakes over a period of 28 years. Freshwater Biology 49: 98-115.

Bell, G., 2005. The co-distribution of species in relation to the neutral theory of community ecology. Ecology 86: 1757-1770.

Cadotte, M., C. H. Albert \& S. C. Walker, 2013. The ecology of differences: assessing community assembly with trait and evolutionary distances. Ecology letters 16: 1234-1244.

Cardinale, B. J., J. E. Duffy, A. Gonzalez, D. U. Hooper, C. Perrings, P. Venail, A. Narwani, G. M. Mace, D. Tilman, D. A. Wardle, A. P. Kinzig, G. C. Daily, M. Loreau, J. B. Grace, A. Larigauderie, D. S. Srivastava \& S. Naeem, 2012. Biodiversity loss and its impact on humanity. Nature 486: 59-67. 
Cavender-Bares, J., K. H. Kozak, P. V. A. Fine \& S. W. Kembel, 2009. The merging of community ecology and phylogenetic biology. Ecology Letters 12: 693-715.

Chase, J. M. \& J. A. Myers, 2011. Disentangling the importance of ecological niches from stochastic processes across scales. Philosophical Transactions of the Royal Society of London Series B, Biological sciences 366: 23512363.

Cleveland, R. B., W. S. Cleveland, J. E. McRae \& I. Terpenning, 1990. STL: A seasonal-trend decomposition procedure based on loess. Journal of Official Statistics 6: 3-73.

Colwell, R. K. \& T. F. Rangel, 2009. Hutchinson's duality: the once and future niche. Proceedings of the National Academy of Sciences of the United States of America 106(Suppl): 19651-19658.

Diamond, J. M., 1975. Assembly of species communities. In Diamond, J. M. \& M. L. Cody (eds.), Ecology and Evolution of Communities. Belknap Press of Harvard University Press, Cambridge, MA: 342-444.

Durham, W. M. \& R. Stocker, 2012. Thin phytoplankton layers: Characteristics, mechanisms, and consequences. Annual Review of Marine Science 4: 177-207.

Edwards, K. F. \& J. J. Stachowicz, 2011. Spatially stochastic settlement and the coexistence of benthic marine animals. Ecology 92: 1094-1103.

Edwards, K. F., E. Litchman \& C. A. Klausmeier, 2012. Functional traits explain phytoplankton community structure and seasonal dynamics in a marine ecosystem. Ecology Letters 16: 56-63.

Edwards, K. F., E. Litchman \& C. A. Klausmeier, 2013. Functional traits explain phytoplankton responses to environmental gradients across lakes of the United States. Ecology 94: $1626-1635$.

Emerson, B. C. \& R. G. Gillespie, 2008. Phylogenetic analysis of community assembly and structure over space and time. Trends in Ecology \& Evolution 23: 619-630.

Fraley, C. \& A. E. Raftery, 2002. Model-based clustering, discriminant analysis and density estimation. Journal of the American Statistical Association 97: 611-631.

Fukami, T., 2010. Community assembly dynamics in space. In Verhoef, H. A. \& P. J. Morin (eds), Community Ecology: Processes, Models, and Applications. Oxford University Press, Oxford: 45-54.

Gotelli, N. J., 2000. Null model analysis of species co-occurrence patterns. Ecology 81: 2606-2621.

Gotelli, N. J. \& D. J. McCabe, 2002. Species Co-occurrence: A meta-analysis of J. M. Diamond's assembly rules model. Ecology 83: 2091.

Gravel, D., F. Guichard \& M. E. Hochberg, 2011. Species coexistence in a variable world. Ecology Letters 14: 828-839.

Hart, S. P. \& D. J. Marshall, 2009. Spatial arrangement affects population dynamics and competition independent of community composition. Ecology 90: 1485-1491.

Hautier, Y., P. A. Niklaus \& A. Hector, 2009. Competition for light causes plant biodiversity loss after eutrophication. Science 324: 636-638.

HilleRisLambers, J., P. B. Adler, W. S. Harpole, J. M. Levine \& M. M. Mayfield, 2012. Rethinking community assembly through the lens of coexistence theory. Annual Review of Ecology, Evolution, and Systematics 43: 227-248.
Jochimsen, M. C., R. Kümmerlin, D. Straile \& J. Grover, 2012. Compensatory dynamics and the stability of phytoplankton biomass during four decades of eutrophication and oligotrophication. Ecology Letters 16: 81-89.

Kathleen Lyons, S., K. L. Amatangelo, A. K. Behrensmeyer, A. Bercovici, J. L. Blois, M. Davis, W. A. DiMichele, A. Du, J. T. Eronen, J. Tyler Faith, G. R. Graves, N. Jud, C. Labandeira, C. V. Looy, B. McGill, J. H. Miller, D. Patterson, S. Pineda-Munoz, R. Potts, B. Riddle, R. Terry, A. Tóth, W. Ulrich, A. Villaseñor, S. Wing, H. Anderson, J. Anderson, D. Waller \& N. J. Gotelli, 2015. Holocene shifts in the assembly of plant and animal communities implicate human impacts. Nature 529: 80-83.

Klausmeier, C. A. \& E. Litchman, 2001. Algal games: The vertical distribution of phytoplankton in poorly mixed water columns. Limnology and Oceanography 46: 1998-2007.

Kraft, N. J. B. \& D. D. Ackerly, 2010. Functional trait and phylogenetic tests of community assembly across spatial scales in an Amazonian forest. Ecological Monographs 80: 401-422.

Kraft, N. J. B., P. B. Adler, O. Godoy, E. C. James, S. Fuller \& J. M. Levine, 2014. Community assembly, coexistence and the environmental filtering metaphor. Functional Ecology 29(5): 592-599.

Kremer, C. T., J. P. Gillette, L. G. Rudstam, P. Brettum \& R. Ptacnik, 2014. A compendium of cell and natural unit biovolumes for $>1200$ freshwater phytoplankton species. Ecology 95: 2984-2984.

Leibold, M. A., M. Holyoak, N. Mouquet, P. Amarasekare, J. M. Chase, M. F. Hoopes, R. D. Holt, J. B. Shurin, R. Law, D. Tilman, M. Loreau \& A. Gonzalez, 2004. The metacommunity concept: a framework for multi-scale community ecology. Ecology Letters 7: 601-613.

Litchman, E. \& C. A. Klausmeier, 2008. Trait-based community ecology of phytoplankton. Annual Review of Ecology, Evolution, and Systematics 39: 615-639.

Livingston, G. F. \& S. M. Philpott, 2010. A metacommmunity approach to co-occurrence patterns and the core-satellite hypothesis in a community of tropical arboreal ants. Ecological Research 25: 1129-1140.

Livingstone, D. M., 2003. Impact of secular climate change on the thermal structure of a large temperate central European lake. Climatic Change 57: 205-225.

Longhi, M. L. \& B. E. Beisner, 2009. Environmental factors controlling the vertical distribution of phytoplankton in lakes. J Plankton Res 31: 1195-1207.

Magurran, A. E., S. R. Baillie, S. T. Buckland, J. M. Dick, D. A. Elston, E. M. Scott, R. I. Smith, P. J. Somerfield \& A. D. Watt, 2010. Long-term datasets in biodiversity research and monitoring: assessing change in ecological communities through time. Trends in Ecology \& Evolution 25: 574-582.

Matthews, B. \& F. Pomati, 2012. Reversal in the relationship between species richness and turnover in a phytoplankton community. Ecology 93: 2435-2447.

Mayfield, M. M. \& J. M. Levine, 2010. Opposing effects of competitive exclusion on the phylogenetic structure of communities. Ecology Letters 13: 1085-1093.

Mittelbach, G. G., C. F. Steiner, S. M. Scheiner, K. L. Gross, H. L. Reynolds, R. B. Waide, M. R. Willig, S. I. Dodson \& L. 
Gough, 2001. What is the observed relationship between species richness and productivity? Ecology 82: 2381-2396.

Padisák, J., L. Crossetti \& L. Naselli-Flores, 2009. Use and misuse in the application of the phytoplankton functional classification: a critical review with updates. Hydrobiologia 621: 1-19.

Pomati, F., B. Matthews, J. Jokela, A. Schildknecht \& B. W. Ibelings, 2012. Effects of re-oligotrophication and climate warming on plankton richness and community stability in a deep mesotrophic lake. Oikos 121: 1317-1327.

Pomati, F., N. J. B. Kraft, T. Posch, B. Eugster, J. Jokela \& B. W. Ibelings, 2013. Individual cell based traits obtained by scanning flow-cytometry show selection by biotic and abiotic environmental factors during a phytoplankton spring bloom. PloS one 8: e71677.

Pomati, F., C. Tellenbach, B. Matthews, P. Venail, B. W. Ibelings \& R. Ptacnik, 2015. Challenges and prospects for interpreting long-term phytoplankton diversity changes in Lake Zurich (Switzerland). Freshwater Biology 60(5): 1052-1059.

Posch, T., O. Köster, M. M. Salcher \& J. Pernthaler, 2012. Harmful filamentous cyanobacteria favoured by reduced water turnover with lake warming. Nature Climate Change 2: $1-5$.

R-Development-Core-Team, 2015. R: A language and environment for statistical computing. R Foundation for Statistical Computing http://www.R-project.org/.

Reynolds, C. S., 2006. Ecology of Phytoplankton. Cambridge University Press, Cambridge.

Reynolds, C. S., V. Huszar, C. Kruk, L. Naselli-Flores \& S. Melo, 2002. Towards a functional classification of the freshwater phytoplankton. J Plankton Res 24: 417-428.

Rosindell, J., S. P. Hubbell \& R. S. Etienne, 2011. The unified neutral theory of biodiversity and biogeography at age ten. Trends in ecology \& evolution 26: 340-348.

Ryabov, A. B. \& B. Blasius, 2011. A graphical theory of competition on spatial resource gradients. Ecology Letters 14: 220-228.
Scheffer, M. \& E. H. van Nes, 2006. Self-organized similarity, the evolutionary emergence of groups of similar species. Proceedings of the National Academy of Sciences of the United States of America 103: 6230-6235.

Seehausen, O. \& D. Schluter, 2004. Male-male competition and nuptial-colour displacement as a diversifying force in Lake Victoria cichlid fishes. Proceedings of The Royal Society B: Biological Sciences 271: 1345-1353.

Shen, G., M. Yu, X. Hu, X. Mi, H. Ren, I. Sun \& K. Ma, 2009. Species-area relationships explained by the joint effects of dispersal limitation and habitat heterogeneity. Ecological Research 90: 3033-3041.

Stomp, M., J. Huisman, F. De Jongh, A. J. Veraart, D. Gerla, M. Rijkeboer, B. W. Ibelings, U. I. A. Wollenzien \& L. J. Stal, 2004. Adaptive divergence in pigment composition promotes phytoplankton biodiversity. Nature 432: 104-107.

Vergnon, R., E. H. van Nes \& M. Scheffer, 2012. Emergent neutrality leads to multimodal species abundance distributions. Nature Communications 3: 663.

Vonlanthen, P., D. Bittner, A. G. Hudson, K. A. Young, R. Müller, B. Lundsgaard-Hansen, D. Roy, S. Di Piazza, C. R. Largiader \& O. Seehausen, 2012. Eutrophication causes speciation reversal in whitefish adaptive radiations. Nature 482: 357-362.

Weiher, E., D. Freund, T. Bunton, A. Stefanski, T. Lee \& S. Bentivenga, 2011. Advances, challenges and a developing synthesis of ecological community assembly theory. Philosophical transactions of the Royal Society of London Series B, Biological sciences 366: 2403-2413.

White, E. P., S. K. M. Ernest, P. B. Adler, A. H. Hurlbert \& S. K. Lyons, 2010. Integrating spatial and temporal approaches to understanding species richness. Philosophical transactions of the Royal Society of London Series B, Biological sciences 365: 3633-3643. 